\title{
The Rise of Cell Therapy Trials for Stroke: Review of Published and Registered Studies
}

\author{
Paulo Henrique Rosado-de-Castro, Pedro Moreno Pimentel-Coelho, ${ }^{2}$ Lea Mirian Barbosa da Fonseca, ${ }^{1}$ \\ Gabriel Rodriguez de Freitas, ${ }^{2,3}$ and Rosalia Mendez-Otero ${ }^{2}$
}

Stroke is the second leading cause of death and the third leading cause of disability worldwide. Approximately 16 million first-ever strokes occur each year, leading to nearly 6 million deaths. Nevertheless, currently, very few therapeutic options are available. Cell therapies have been applied successfully in different hematological diseases, and are currently being investigated for treating ischemic heart disease, with promising results. Recent preclinical studies have indicated that cell therapies may provide structural and functional benefits after stroke. However, the effects of these treatments are not yet fully understood and are the subject of continuing investigation. Meanwhile, different clinical trials for stroke, the majority of them small, nonrandomized, and uncontrolled, have been reported, and their results indicate that cell therapy seems safe and feasible in these conditions. In the last 2 years, the number of published and registered trials has dramatically increased. Here, we review the main findings available in the field, with emphasis on the clinical results. Moreover, we address some of the questions that have been raised to date, to improve future studies.

\section{Introduction}

$\mathrm{S}$ TROKE IS RESPONSIBLE FOR $\sim 11.1 \%$ of all deaths, and is the second leading cause of death worldwide after ischemic heart disease [1]. After a stroke, roughly a quarter of patients die within a month, and half within 1 year [2]. There were an estimated 16 million first-ever strokes and 5.7 million deaths in 2005 [3]. These numbers are expected to increase to 23 million first-ever strokes and 7.8 million deaths in 2030 [3]. Stroke was responsible for 102 million disability-adjusted life years (DALYs) in 2010, an increase to the third leading cause of DALYS from the fifth leading cause in 1990 [4]. Approximately $80 \%$ of all strokes are ischemic, and currently, tissue plasminogen activator (tPA) is the only pharmacological agent approved for treatment of acute ischemic stroke. However, tPA therapy has important limitations, notably the narrow therapeutic window of $4.5 \mathrm{~h}$, which limits its use to a small minority ( $2 \%$ to $4 \%$ ) of patients [5]. Moreover, tPA prevents disability in only six patients per 1000 ischemic strokes, and does not reduce the mortality rate [6]. The administration of aspirin within $48 \mathrm{~h}$ of onset of ischemic stroke decreases the mortality rate or the incidence of disability in about nine patients per 1000 treated, probably due to early secondary prevention [2]. The injury produced by stroke is largely complete after $24-48 \mathrm{~h}$, and neuroprotective therapies that must be administered within a time window such as 3-6h are difficult to apply in clinical practice [7]. On the other hand, neurorestorative therapies, including cell therapies, seek to enhance regenerative mechanisms such as angiogenesis, neurogenesis, and synaptogenesis, and have been investigated extensively in the preclinical models of ischemia $[7,8]$. Neurorestorative cell therapies can be grossly divided into endogenous or exogenous. Endogenous therapies are those that aim to stimulate, for example, bone marrow-cell migration to the blood stream, with pharmacological agents such as granulocyte-colony stimulating factor (G-CSF). The exogenous approach involves the injection of a variety of cells to produce structural or functional benefits, and will be the focus of this article. Although excellent reviews have been recently made on different aspects of cell therapies for stroke [9-13], there has been a dramatic increase in the number of published and registered trials in the past years that has not been comprehensively assessed. In the following sections, we will review the main preclinical and clinical results to date and comment on some of the questions that have been raised.

\section{Main Cell Types Used in Neurorestorative Cell Therapies for Stroke}

\section{Neural stem/progenitor cells}

Neural stem/progenitor cells (NSPC) are cells with a selfrenewing capacity and the potential to generate neurons and glial cells. NSPC can be isolated from the fetal brain or from one of the two neurogenic niches that persist in the adult

\footnotetext{
${ }^{1}$ Hospital Universitário Clementino Fraga Filho, Universidade Federal do Rio de Janeiro, Rio de Janeiro, Brazil.

${ }^{2}$ Instituto de Biofísica Carlos Chagas Filho, Universidade Federal do Rio de Janeiro, Rio de Janeiro, Brazil.

${ }^{3} \mathrm{D}^{\prime}$ Or Institute for Research and Education, Rio de Janeiro, Brazil.
} 
brain: the subventricular zone of the lateral ventricles and the hippocampal subgranular zone [14-16]. Despite the evidence that transplanted fetal NSPC can functionally integrate into the brain of patients with Parkinson's disease [17], there are several obstacles to the use of NSPC from these two sources in clinical trials in stroke. For instance, the need for multiple fetal donors to treat a single patient could raise ethics concerns and may not be feasible in large-scale trials. Moreover, the isolation of adult NSPC for autologous transplantation would require brain biopsies and many days in culture for expansion, and may have some limitations, given that adult NSPC are regionally specified to generate a limited number of neuronal subtypes, even after cerebral ischemia [18].

NSPC can also be generated from pluripotent stem cells, including embryonic stem cells (ES, derived from the inner cell mass of blastocysts) and induced pluripotent stem cells (iPS, obtained after epigenetic reprogramming of adult cells by a combination of transcription factors). In each case, NSPC can be expanded in vitro, forming floating cell clusters called neurospheres, composed of a heterogeneous population of proliferating cells, which can be induced to differentiate into diverse phenotypes of the neuronal or glial lineage. However, the clinical use of ES-derived NSPC is still associated with the risks of neural overgrowth or teratoma formation, if undifferentiated ES persist in the transplant pool [19]. In addition, transplantation of allogeneic NSPC grafts requires immunosuppression, which is also associated with several side effects.

iPS-derived NSPC can be obtained after reprogramming of somatic cells from the patient himself, allowing an autologous transplantation. Although a recent study has cautioned that mouse iPS-derived teratomas can trigger immunogenicity in matched mice through a T-cell immune response [20], immunogenicity may not occur when ES- or iPS-derived terminally differentitated cells are transplanted [21]. Nevertheless, the creation of public banks of human leukocyte antigen-typed ES- or iPS-derived cell lines (and their differentiated cells) could be a more practical form of generating these cells using good manufacturing practices, at the appropriate time for transplantation, while reducing the immunogenicity of NSPC [22]. Other potential sources of neural cells for transplantation include induced neuronal cells and induced NSPC generated directly from fibroblasts or other somatic cells by a combination of transcription factors [23-25]. Human teratocarcinoma-derived neurons have also been used in clinical trials in stroke, as discussed below [26-30].

\section{Non-NSPC}

Mesenchymal stem cells (MSC) and hematopoietic stem/ progenitor cells (HSPC) are the two non-neural cell types that are most frequently used in preclinical and clinical neurorestorative studies in stroke.

HSPC can be isolated from bone marrow or from umbilical-cord blood (UCB), or can be mobilized into the blood by the administration of pharmacological agents such as G-CSF and plerixafor. Most of the studies in animal models of stroke have transplanted the whole mononuclear cell (MNC) fraction from one of these sources, which also contains other cell types, including monocytes and lymphocytes, in addition to HSPC, MSC, and endothelial progenitor cells [31].
Alternatively, a smaller group of studies have transplanted human $\mathrm{CD}_{34}{ }^{+}$MNCs, a subpopulation enriched in HSPC and endothelial progenitor cells.

MSC are multipotent cells with the capacity to give rise to cells of the osteogenic, chondrogenic, and adipogenic lineages. MSC can be isolated, and the culture expanded from several tissues, including bone marrow, adipose tissue, and UCB. Although a set of minimal criteria defined by the International Society for Cellular Therapy can be used to identify MSC, there are some functional and phenotypic differences among MSC derived from different sources [32,33].

\section{Potential Mechanisms of Action of Cell-Based Therapies in Stroke}

\section{Neural stem/progenitor cells}

Intracerebrally administered human NSPC migrate toward the sites of injury in the ischemic brain [34], where they survive for up to 2 months and differentiate into functional neurons, astrocytes, and oligodendrocytes [35]. However, the need to generate several neuronal subtypes that must extend long axons and form the appropriate synaptic connections is still one of the main challenges in regenerative medicine, and has been extensively reviewed elsewhere [13,36].

In addition to the potential of NSPC to replace the lost neurons, recent preclinical studies have observed that part of the therapeutic effects of NSPC in the ischemic brain could be attributed to a paracrine mechanism, since NSPC constitutively express mRNA and secrete several neurotrophic and growth factors in vitro [37-39]. For example, it has been shown that human NSPC transplantation increases neovascularization and enhances the integrity of the blood-brain barrier after stroke, through a human vascular endothelial growth factor (VEGF)-dependent mechanism [40]. VEGF is also one of the main factors involved in the modulatory role of an NSPC-derived conditioned medium in microglia function [41]. Accordingly, NSPC remain in close contact with microglial cells, even when injected into the brain of control animals [34], suggesting that a similar mechanism may occur in vivo [41].

Interestingly, NSPC transplantation contributes to the functional recovery in animal models of stroke, independent of the route of injection [42-44]. NSPC migrate to the sites of injury, even when intra-arterially delivered, and this recruitment is dependent on the chemokine receptor CCR2 $[43,45]$. In contrast, intravenous (IV) transplantation of NSPC results only in marginal migration of cells to the damaged brain, and in an animal model of intracerebral hemorrhage, the injected NSPC migrated mainly to the spleen. Nevertheless, the treatment resulted in the reduction of inflammation, edema formation, and apoptosis in the brain. Since these effects were not observed in splenectomized animals, the authors suggested that NSPC could provide neuroprotection by modulating the inflammatory response in the spleen [46].

Similarly, despite the low levels of engraftment and neuronal differentiation in the ischemic brain, intravenously transplanted adult NSPC showed neuroprotective and antiinflammatory effects in a rodent model of stroke [42]. 
Taken together, these studies provide evidence that besides neuronal replacement, NSPC could contribute to functional recovery after a stroke by a combination of mechanisms, including neuroprotection and immunomodulation. NSPC could also stimulate endogenous mechanisms of brain plasticity and regeneration, enhancing hippocampal neurogenesis [47], stimulating the repair of the neurovascular unit [40], rescuing axonal transport, and inducing dendritic plasticity and axonal sprouting [38].

\section{Non-NSPC}

Although it has been proposed that HSPC and MSC could differentiate into neural cells in vitro, HSPC- or MSC-derived neuronal-like cells do not fire action potentials [48,49], and this phenomenon has not been reproduced in vivo [50,51]. An interesting study has estimated that only a small fraction (around $0.02 \%$ ) of intravenously injected bone marrowderived HSPC migrate to the ischemic brain, where most of the transplanted cells adopt a macrophage/microglial phenotype. In spite of this, HSPC transplantation decreases the infarct size and reduces inflammation in the brain and the spleen of the treated animals [51]. Moreover, it has been observed that MSC only transiently engraft the ischemic brain after an intra-arterial infusion [52], and that systemically delivered UCB-MNCs promote the behavioral recovery in an animal model of stroke, despite the low engraftment level in the host brain [53]. In summary, MSCs, bone marrow MNCs (BM-MNCs), and UCB-MNCs can improve neurological function in several models of stroke, through a combination of effects, such as neuroprotection, immunomodulation, and stimulation of neural plasticity [54-64], but these effects are not necessarily due to the presence of the cells at the injury site. In addition, MSC and HSPC transplantation can also induce angiogenesis and neurogenesis in the ischemic brain $[65,66]$, two processes that are tightly linked by several regulatory mechanisms [67]. These mechanisms of action seem to rely on the secretion of neurotrophic factors and immunomodulatory molecules by the transplanted cells $[68,69]$, an effect that can be further modulated by the host microenvironment. A recent study has raised the possibility that MSC could also exert their therapeutic actions by a mechanism of exosome-mediated transfer of microRNAs to neurons and astrocytes. Interestingly, the microRNA 133b levels in MSC exosomes increased when these cells were exposed to the ischemic brain extracts [70]. Thus, the transient engraftment of the transplanted cells and the dynamic changes that occur in the ischemic brain during the repair process may suggest that multiple injections may be required to optimize the release of the appropriate factors by the injected cells [71]. In addition, stroke-induced systemic inflammation can also modulate the phenotype of the BM-MNC populations, improving their potential to induce recovery after cerebral ischemia, if the cells are harvested and transplanted on the first day after the insult [72]. Hence, it is still necessary to evaluate the best timing for bone marrow harvest after stroke, in the case of autologous transplantation.

Finally, endothelial progenitor cells can be isolated and the culture expanded from the peripheral blood or from the UCB. These cells home to the ischemic brain through a stromal-derived factor 1-dependent mechanism, reducing the infarct size and improving the neurological outcome in mice [73]. The coadministration of culture-expanded UCBderived endothelial and smooth-muscle progenitor cells has also been shown to increase angiogenesis and neurogenesis in an animal model of stroke [74]. Therefore, preclinical studies comparing the efficacy of endothelial progenitor cells, MSC, and HSPC from different sources are needed. In this regard, it has been shown that an intravenous administration of bone marrow-derived MSC promotes a similar degree of functional recovery to bone marrow-derived mononuclear cell transplantation in a rodent model of stroke, as long as the dose is optimized for each cell type [59]. Another study showed that there was no difference in the therapeutic effects of bone marrow-derived and umbilical cord tissue-derived MSCs (UC-MSCs) in a model of focal ischemia [75].

\section{Published Clinical Trials}

We found 31 articles in the English language involving 20 different trials of cell therapies for stroke, with a total of 243 treated patients. Sixteen of these articles and 12 of the trials were published in the last 2 years. Twelve trials were for ischemic, two for hemorrhagic, and six for ischemic or hemorrhagic strokes (Table 1 and Fig. 1). Six trials performed intravenous transplants; five injected the cells in the parenchyma; five used the intra-arterial route; three carried out intrathecal administrations; and one trial compared intraarterial and intravenous routes (Table 1 and Fig. 1).

\section{Trials with Intracerebral Administration}

\section{Human teratocarcinoma-derived neurons}

Kondziolka et al. [26] conducted the first clinical trial of cell therapy for stroke. It involved the transplantation of LBSNeurons (Layton BioScience, Inc., Sunnyvale, CA), derived from a human teratocarcinoma cell line (NT2N) that was induced to differentiate into neurons by the addition of retinoic acid. This phase I, nonrandomized, observer-blind study included 12 patients with basal ganglia stroke and fixed motor deficits that occurred 6 months to 6 years before the transplantation. Eight of these patients received a total of 2 million cells, divided into three injections, into the area of the infarction, and the other four patients received 6 million cells divided into nine implants. Immunosuppression was accomplished with cyclosporine A started 1 week before surgery and continued for 8 weeks. One patient had a single generalized seizure 6 months after surgery, and another patient had a new brainstem stroke distant from the area of neuronal cell transplantation. However, these complications were thought not to be connected to the procedure, and no cell-related adverse effects were observed in the 5-year follow-up. Seven of 11 positron-emission tomography (PET) scans carried out at 6 months indicated an increase in fluorodeoxyglucose uptake at the implant site, while at 12 months, this number decreased to three [30]. The authors suggested that this could be related to cell viability in the area of the stroke, or alternatively to increased metabolic activity due to an inflammatory process, although no modifications indicative of inflammation were seen on magnetic resonance imaging (MRI). The procedure was evaluated as safe and feasible, and autopsy on one patient who died of 


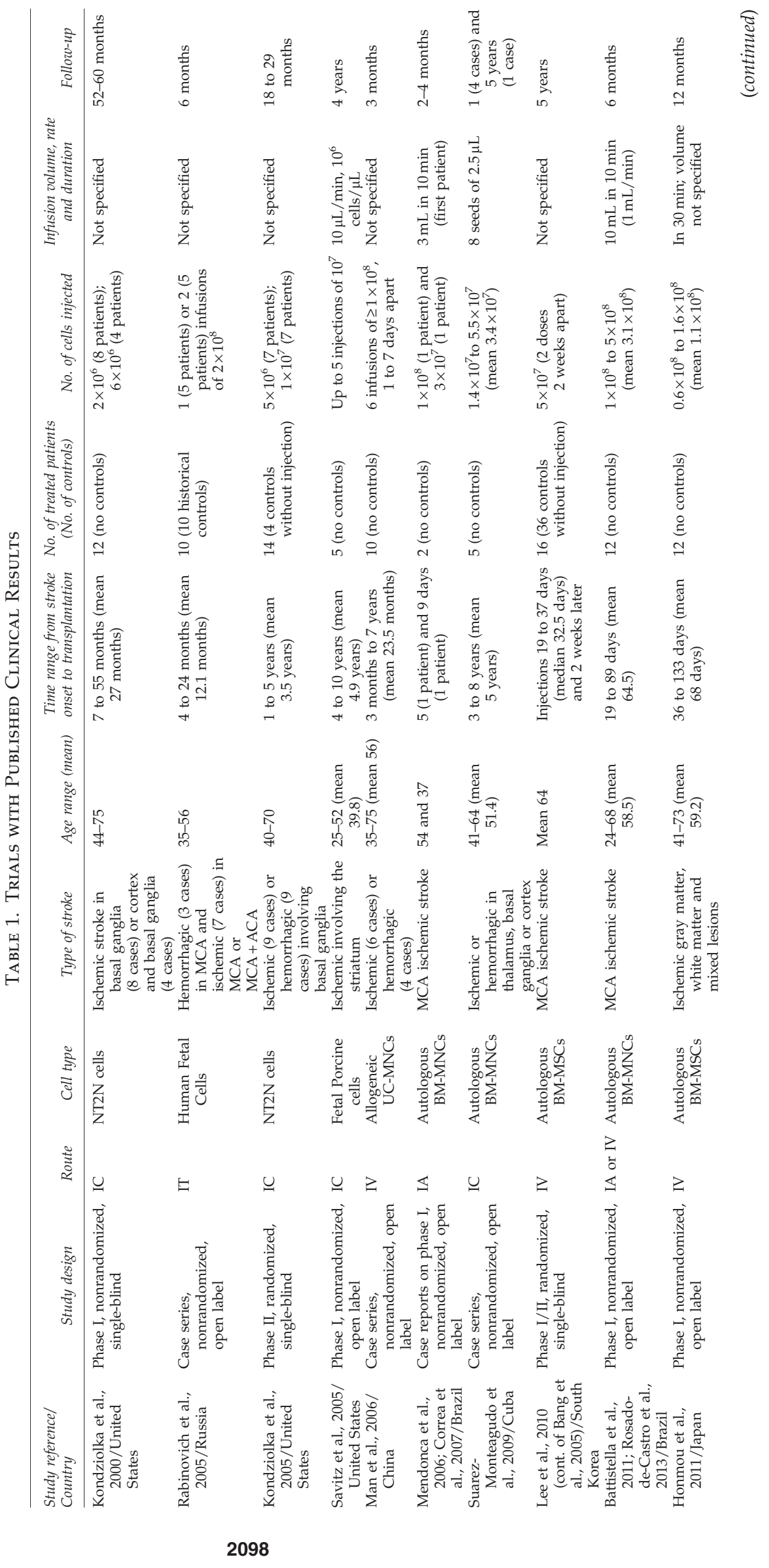




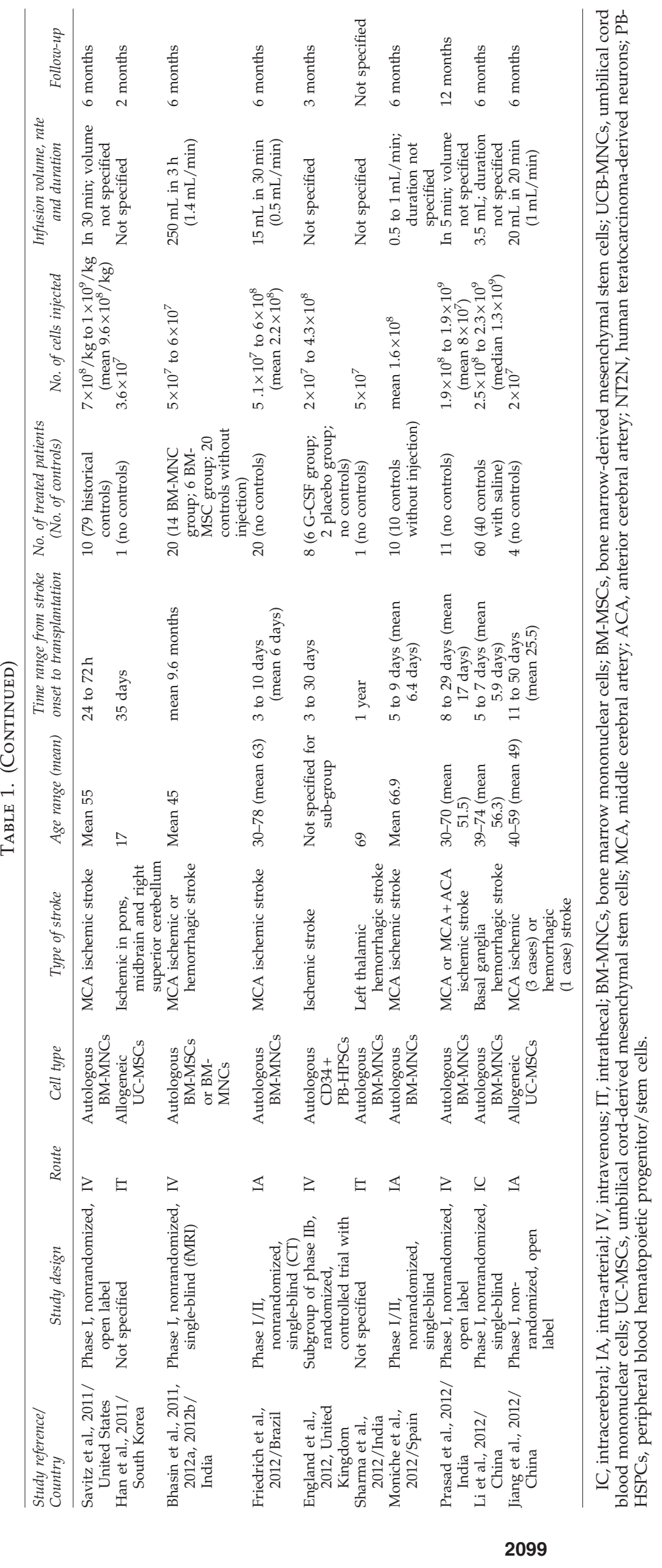




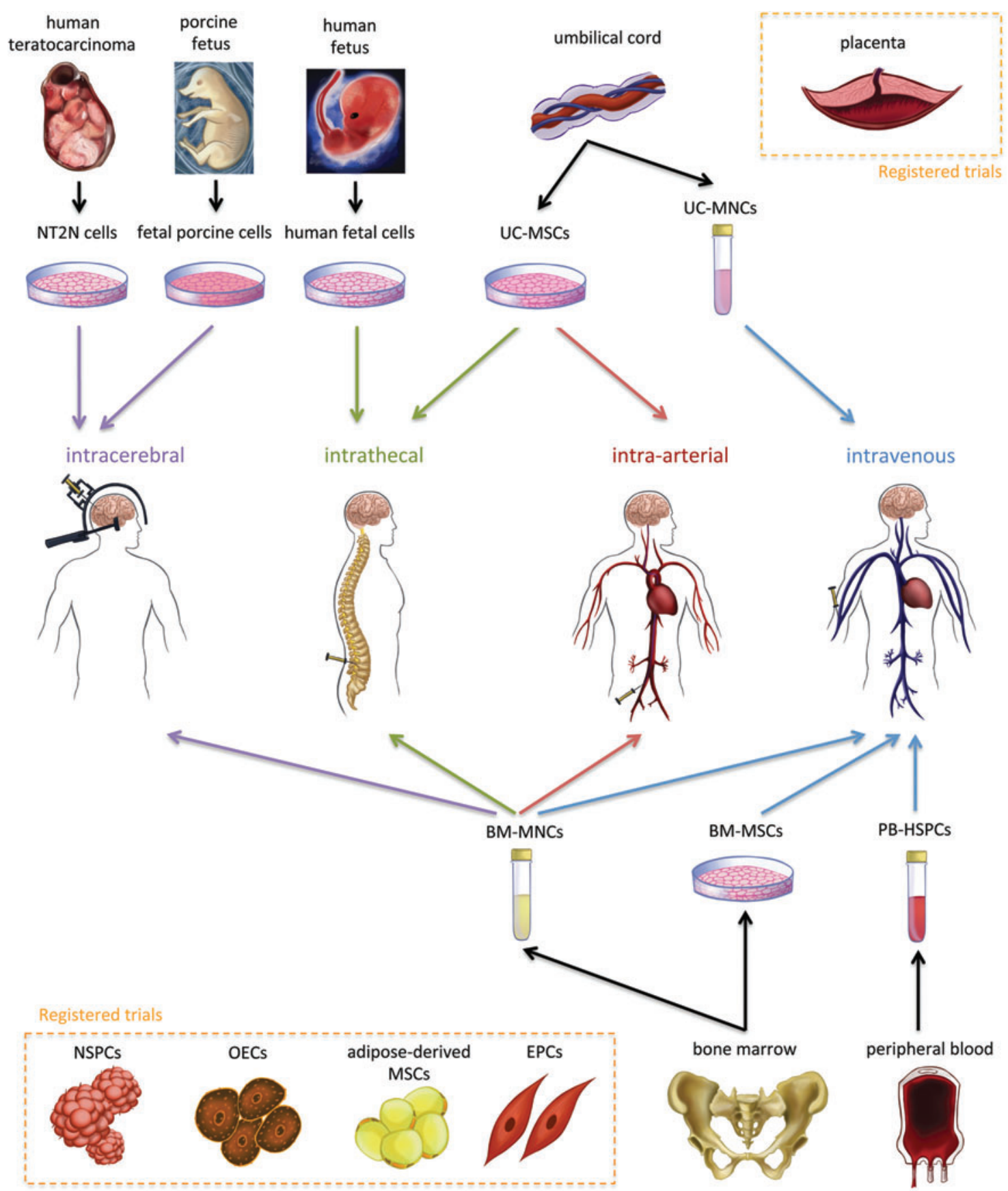

FIG. 1. Schematic illustrating the different cells and routes of administration used in published trials. The schematic also illustrates other types of cells used in registered trials (in dotted rectangles). NT2N, human teratocarcinoma-derived neurons; UC-MSCs, umbilical cord-derived mesenchymal stem cells; UCB-MNCs, umbilical cord blood-mononuclear cells; BM-MNCs, bone marrow-mononuclear cells; BM-MSCs, bone marrow-mesenchymal stem cells; PB-HSPC, peripheral blood-hematopoietic stem/progenitor cell; NSPCs, neural stem/progenitor cells; OECs, olfactory-ensheathing cells; MSCs, mesenchymal stem cells; EPCs, endothelial progenitor cells. Color images available online at www.liebertpub.com/scd

myocardial infarction 27 months after cell transplantation showed that NT2N cells survived in the brain [28].

This trial was followed by a phase II, randomized, singleblind trial that included nine patients with ischemic and nine with hemorrhagic strokes from 1 to 6 years previously and with a fixed motor deficit that was stable for at least 2 months [29]. Seven patients received 5 million cells and seven patients 10 million cells, distributed in 25 sites, while 4 patients served as a nonsurgical control group; all subjects participated in a stroke rehabilitation program. One patient suffered a single seizure the day after the surgery, and another presented a burr-hole drainage of an asymptomatic chronic subdural hematoma 1 month after surgery. There was no significant improvement in the primary endpoint outcome, that is, European Stroke Scale motor score or the Fugl-Meyer (FM) Stroke Assessment, but there was 
improvement in the Action Research Arm Test gross handmovement scores compared with the control and baseline values.

\section{Fetal porcine cells}

Savitz et al. [76] carried out stereotactic implantation of fetal porcine cells in five patients with basal ganglia infarcts, after pretreatment of the cells with an anti-MHC1 antibody. No immunosuppressants were administered. One patient presented transitory deterioration of motor deficits 3 weeks after cell implantation, and another patient had seizures 1 week after therapy. The study was initially designed to enroll 12 patients, but the FDA (U.S. Food and Drug Administration) ended it due to safety concerns.

\section{Autologous BM-MNCs}

Suarez-Monteagudo et al. [77] performed a trial with intracerebral transplantation of BM-MNCs, which included three patients with ischemic strokes in the thalamus, striatum, or cortex, and two patients with hemorrhagic strokes in the thalamus or striatum, from 3 to 8 years after the lesion. A total of $1.4 \times 10^{7}$ to $5.5 \times 10^{7} \mathrm{BM}-\mathrm{MNC}$ s were stereotactically implanted along several tracts around the lesion. There were no important adverse effects during the 1-year follow-up. The authors also reported significant neurological improvements at 12 months in comparison to baseline, with a reduction in motor defect evaluated by the Medical Research Council Scale and Ashworth's Scale for Spasticity; increased functional capacity evaluated by the Barthel index (BI); improved neurological condition evaluated by the National Institutes of Health Stroke Scale (NIHSS) and the Scandinavian Stroke Scale; and better equilibrium and locomotion, evaluated by the Tinneti scale. The same group [78] later reported the 5-year neuropsychological follow-up of one of the patients of the previous study and reported that positive cognitive changes in verbal and executive functions were maintained and seemed to be related to increased blood flow to the prefrontal areas. However, the unblind evaluation, the lack of a control group, and the small sample size did not allow definitive conclusions regarding efficacy.

In the largest clinical trial up to now, Li et al. [79] described a phase I, nonrandomized, single-blind study in which 60 patients received intraparenchymal BM-MNC transplantation 5 to 7 days after basal ganglion hemorrhagic stroke, and 40 patients formed the control group. Administered doses ranged from $2.5 \times 10^{8}$ to $2.3 \times 10^{9}$ cells. At 6 months after transplantation, the NIHSS score in the treated patients was significantly lower than in the control group, while the BI scores were higher. Moreover, there was significant neurological and functional improvement in BMMNC-treated patients $(86.7 \%$ versus $42.5 \%$ in the control group, $P=0.001)$.

\section{Trials with Intrathecal Administration}

\section{Human fetal cells}

Rabinovich et al. [80] reported on a case-series, nonrandomized, open-label study that included three patients with hemorrhagic strokes in the middle cerebral artery (MCA) territory and seven patients with ischemic strokes in the MCA territory, with or without additional involvement of the anterior cerebral artery (ACA) territory. Subarachnoidal injections of $2 \times 10^{8}$ human fetal cells were made between 4 and 24 months after the disease onset. The cells were obtained from human fetuses after spontaneous or prostaglandin-induced abortions, and were described as a 10:1 ratio of nerve cells to hemopoetic hepatic cells. The authors reported that some patients had fever and meningism during $48 \mathrm{~h}$ after transplantation. Although a retrospective control group of 11 patients was described, the measures of outcome were not adequately explained, thus not permitting comparisons between the two groups. Moreover, the study lacks a detailed characterization of the phenotype of the transplanted cells.

\section{Autologous BM-MNCs}

Sharma and collaborators [81] described a case report in which $5 \times 10^{7}$ BM-MNCs were injected intrathecally in a patient 1 year after an hemorrhagic stroke. Even though there was no control group and only one patient was included, the authors attributed improvements in cognition, motor function, and activities of daily living to the cell transplantation. The follow-up period was not specified.

\section{Allogeneic umbilical cord-MSCs}

Han et al. [82] intrathecally injected $3.6 \times 10^{7}$ UC-MSCs in a patient 35 days after a basilar artery dissection that caused an infarction in the pons, midbrain, and right superior cerebellum. Two other injections were performed 15 and 41 days after the first treatment. Although the neurological and imaging were followed-up for only 2 months and in only one patient, the authors concluded that the improvement of clinical symptoms and a recanalization of the basilar artery were helped by the cell transplantation.

\section{Trials with Intra-Arterial Administration}

\section{Autologous BM-MNCs}

The first reports of studies using BM-MNC therapy for stroke were published from 2005 to 2007 [83-85] and were part of a nonrandomized, open-label phase I study. In the first case report $[83,84]$, a 54-year-old patient was treated with intra-arterial injection of $3 \times 10^{7}$ BM-MNCs 5 days after an MCA ischemic stroke. A PET carried out 7 days after BMMNC transplantation demonstrated augmented metabolism in the left parietal cortex, which could occur in the presence of transplanted cells or due to local inflammatory processes. In the second case report [85], a 37-year-old patient received $3 \times 10^{7}$ BM-MNCs 9 days after an MCA ischemic stroke. Approximately $1 \%$ of the cells were labeled with Technetium-99m $\left({ }^{99 \mathrm{~m}} \mathrm{Tc}\right)$ by incubation with hexamethylpropylene amine oxime (HMPAO) and delivered together with the rest of the cells. Whole-body images demonstrated high uptake in the left hemisphere, liver, and spleen. Single-photonemission computed tomography (SPECT) images $8 \mathrm{~h}$ after cell transplantation showed that the homing of ${ }^{99 \mathrm{~m}} \mathrm{Tc}$ HMPAO-labeled cells occurred mainly in the territory of the anterior division of the MCA, while the stroke was in the territory of the posterior branch of the left MCA, probably because of the occlusion of the posterior branch. It is important to note that these patients were transplanted in the first 10 days after stroke. 
Barbosa da Fonseca et al. [86,87] and Battistella et al. [88], respectively, reported the imaging and clinical results of a trial that included six patients 59 to 82 days after an MCA ischemic stroke. Afterward, another case where cells were injected 19 days after the stroke was also reported [89]. The cell dose ranged from $1 \times 10^{8}$ to $5 \times 10^{8}$ BM-MNCs, and $\sim 2 \times 10^{7}$ of the cells were labeled with ${ }^{99} \mathrm{~m}$ Tc and delivered intra-arterially together with the unlabeled cells to the MCA. There were no cell-related adverse effects, and the cell uptake was greatest in the liver and lungs. Although cell homing was greater in the ischemic hemisphere, total uptake in the brain was low, $<2 \%$ of the total activity for five of seven patients. Two patients had generalized seizures $\sim 200$ days after cell injection, which were controlled pharmacologically, but due to the small sample, it was not possible to determine if the seizures occurred by chance or due to the cell transplantation.

In a study by Friedrich et al. [90], 20 patients with a moderate-to-severe MCA ischemic stroke received BMMNCs infused intra-arterially between 3 and 7 days after stroke. The injected dose ranged from $5 \times 10^{7}$ to $6 \times 10^{8}$ cells. There were no procedure-related adverse events, and eight patients (40\%) exhibited good clinical outcome, defined as a modified Rankin score (mRS) $\leq 2$ at 90 days. Although the mortality level was below the expected level for similar populations, there was no control group, and the authors could not exclude the possibility that the good results could be explained by chance.

Moniche et al. [91] performed a nonrandomized singleblind phase I/II trial in which 10 patients received an intraarterial injection of BM-MNCs 5 to 9 days after an MCA ischemic stroke, with an untreated control group of 10 patients. The mean infused dose was $1.6 \times 10^{8}$ cells. Two subjects who received BM-MNCs had an isolated partial seizure 3 months after the transplantation, which was considered a serious adverse event. In both patients, an antiepileptic medication was initiated, with no recurrent seizures. No other serious adverse events occurred during the 6-month follow-up. There was no significant improvement in neurological evaluation in comparison with the control patients. Even though there was no association involving the neurological condition and the number of injected BM-MNCs, the authors reported a trend toward a better outcome when a larger amount of CD34 + cells was injected, mainly in the BI at 1 month after cell therapy. Also, higher concentrations of B-nerve growth factor were observed in the serum of BMMNC-treated patients 8 days after cell transplantation.

\section{Allogeneic umbilical cord-MSCs}

Jiang et al. [92] included three patients with ischemic and one with hemorrhagic MCA strokes. One dose of $2 \times 10^{7}$ allogeneic umbilical cord-MSCs was transplanted into the MCA 11 to 50 days after the disease onset. No immunosuppression was used, and the neurological follow-up was not clearly defined; the $\mathrm{mRS}$ score was the only neurological scale analyzed. No adverse events such as fever, stroke, or death were observed during the 6-month follow-up. The authors reported that two of the ischemic patients demonstrated improved mRS scores, while no improvement was seen in the other two patients, which the authors interpreted as an indication that stem cells improved the neurological function after an ischemic, but not after hemorrhagic, stroke. However, the small number of patients and the absence of a control group do not permit such a conclusion regarding the efficacy of the approach.

\section{Trials with Intravenous Administration}

\section{Allogeneic UCB-MNCs}

Man et al. [93] included six patients with ischemic and four with hemorrhagic strokes that occurred 3 to 7 years before transplantation, in a trial for intravenous transplantation of allogeneic human UCB-MNCs. Each patient received six infusions of $\geq 1 \times 10^{8}$ cells, 1 to 7 days apart. Immunosuppressive drugs were not used, and there were no cell-related adverse events during the 3-month follow-up. Patients had a significant improvement in the neurological function deficiency, FM assessment, and BI, but there was no control group for comparison.

\section{Autologous bone marrow-MSCs}

Bang et al. [94] described the first trial with autologous bone marrow-MSCs (BM-MSCs) for stroke. In the first report of this phase I/II randomized controlled trial, 30 patients were prospectively and randomly allocated at the seventh day of admission after stroke. Five patients received two intravenous injections of $5 \times 10^{7}$ cells after culture expansion in fetal calf serum at 4 to 5 and 7 to 9 weeks after an MCA ischemic stroke, 25 patients served as controls, and all patients underwent rehabilitation therapy. At 1-year follow-up, there were no adverse cell-related, serological, or imagingdefined effects, and there was a nonsignificant trend toward improved BI and mRS. Afterward, the same group [95] included a larger number of patients in the same treatment protocol, and received a 5-year follow-up. Sixteen patients were treated, and 36 patients served as controls. No significant side effects were seen during the follow-up, and comorbidities such as seizures and recurrent strokes were similar between the groups. In comparison to the control group, there was a decrease in the mRS score of cell-treated patients. Interestingly, neurological recovery in the BM-MSC patients was related to the extent of involvement of the subventricular zone of the lateral ventricle and to the plasmatic levels of stromal cell-derived factor-1.

In another trial, Honmou et al. [96] included 12 patients with ischemic gray-matter, white-matter, and mixed lesions in a nonrandomized, open-label trial to analyze the effects of autologous BM-MSCs expanded in human serum, without a control group. They found that cell expansion was faster than in fetal bovine serum, which reduced cell preparation time. Also, they stressed that the use of human serum reduced the hazard of transmitting diseases such as bovine spongiform encephalomyelitis. BM-MSCs were infused intravenously 36 to 133 days after the cerebral infarct. There were no cell-related side effects. The authors found that the mean lesion volume as evaluated by MRI decreased by $20 \%$ or more at 1 week after cell therapy. Moreover, the median daily rate of change in the NIHSS increased in the first week after cell transplantation, and tended to be correlated with the decrease in the lesion volume.

Similarly, Bhasin et al. [97] conducted a phase I, nonrandomized, single-blind (for functional imaging interpretation) 
trial where six patients were included with ischemic or hemorrhagic MCA strokes ranging from 7 to 12 months previously, while 6 patients served as controls. After cell culture for 3 weeks in an animal serum-free medium (Stem Pro SFM), an intravenous injection of autologous BM-MSCs was administered. There were no cell-related adverse events during the 6-month followup. Although there was an improvement in the FM and modified $\mathrm{BI}$ at the 2- and 6-month evaluations, there was no statistical difference between the control and BM-MSC-treated groups. Moreover, there were no statistically significant differences in the functional MRI (fMRI) analysis between the BM-MSC and control groups.

\section{Autologous BM-MNCs}

Savitz et al. [98] reported the results of a trial in which 10 patients received an intravenous infusion of $7 \times 10^{6} / \mathrm{kg}$ to $1 \times 10^{7} / \mathrm{kg}$ BM-MNCs 24 to $72 \mathrm{~h}$ after MCA ischemic strokes. Two patients had to undergo hemicraniectomy after cell transplantation, due to infarct expansion between enrollment and bone marrow harvest. One patient died from a pulmonary embolism at 40 days after cell therapy, which was judged to be unrelated to the procedure. There were no study-related severe adverse events.

Prasad et al. [99] carried out a phase I, nonrandomized, open-label trial where 11 patients received an intravenous infusion of BM-MNCs between 8 and 29 days after MCA with or without ACA stroke, with no control group. The injected dose ranged from $1.9 \times 10^{8}$ to $1.9 \times 10^{9}$ cells. No serious adverse event was observed during the study. Seven patients had a favorable clinical outcome, defined as $\mathrm{mRS} \leq 2$ or a BI score of 75 to 100 at 6 months after cell transplantation.

After the first study reporting on the transplantation of BM-MSC for six patients with ischemic or hemorrhagic MCA strokes [97], Bhasin et al. reported on the intravenous transplantation of BM-MNCs for 12 patients, between 3 and 14 months after an MCA ischemic stroke [100]. Twelve patients served as controls. Statistically significant improvement was seen in the modified BI at 6 months and in the Laterality index in ipsilateral Broadmann areas 4 and 6 in fMRI at 2 months, but not at 6 months. The same group also published a comparison of the results of the six treated patients and six controls of the BM-MSC group with 14 treated patients and 14 controls of the BM-MNC group [101]. In this study, they also found statistical improvement in modified BI when comparing BM-MNC-treated patients with controls at 6 months, but no longer found improvement in fMRI. No statistical difference was found between the BM-MNC and BM-MSC groups. No adverse reactions were observed in the study in any of the groups during the follow-up.

Our group recently reported a continuation of the first trial, with intra-arterial administration of BM-MNCs in patients with a subacute stroke. In this study, five patients received an intravenous injection of BM-MNCs labeled with ${ }^{99 \mathrm{~m}}$ Tc. Analysis of the distribution of cells showed that intravenous administration led to higher uptake in the lungs and lower uptake in the liver and spleen at 2 and $24 \mathrm{~h}$, in comparison with the intra-arterial route. Although SPECT images at $2 \mathrm{~h}$ indicated that intravenous injection led to a lower relative uptake in the lesioned hemisphere in comparison with the intra-arterial route, the total uptake in the brain in comparison to the whole body was low, but similar, between the two groups. All of the intravenous patients suffered seizures during the follow-up period, which were controlled pharmacologically. Although it was not possible to rule out that these seizures occurred by chance and/or because of greater stroke severity than the intra-arterial group, the incidence of seizures warrants caution, and these patients are under extended follow-up. It is possible that the infused cells could modify the excitability in the perilesional regions, generating seizures, and this possibility must be examined further in the forthcoming trials.

\section{Autologous CD34+ HSPCs}

England et al. [102] published a trial where 40 patients were included 3 to 30 days after an ischemic or hemorrhagic stroke, to receive subcutaneous injections of G-CSF once per day for 5 days, and 20 patients were treated with a placebo. Eight patients (6 from the G-CSF group and 2 from the placebo group) with ischemic strokes agreed to participate in a substudy, and on day 6 underwent peripheral blood collection with subsequent immunomagnetic separation of CD34 + cells with antibodies containing a dextran-coated iron oxide nanobead. These peripheral blood HSPCs (PBHSPCs) were injected intravenously and could be followed by MRI due to the iron oxide labeling. Patients in the G-CSF group received $5.0 \times 10^{5}$ to $4.3 \times 10^{6} \mathrm{~PB}-\mathrm{HSPCs}$, while the placebo group received 2 to $7 \times 10^{4}$ cells. A hypodensity consistent with iron deposition within the stroke was seen in one G-CSF-treated patient after 10 and 90 days.

\section{Registered Trials}

A search in the National Institutes of Health clinical trial registry (www.clinicaltrials.gov) indicated 25 completed (but unpublished) or ongoing registered studies, which are projected to enroll 1046 patients (Table 2). Of these, an exclusive intravenous, intracerebral, or intra-arterial administration was chosen by 13, 7, and 3 studies, respectively, while one study opted for intravenous and intrathecal, and another for intravenous or intra-arterial routes. The majority of the trials are being conducted in the United States and China, and a total of 16 studies were started in 2011 and 2012 (Fig. 2).

The results available as of yet from the different abovementioned studies suggest that cell therapies with different cell types in stroke seem to be safe and feasible, independently of the route of administration, dose, or time window after the onset of the disease. However, the many differences among them preclude further comparisons.

\section{Discussion}

Several preclinical studies have indicated that there is a structural and/or functional recovery after intracerebral, intra-arterial, and intravenous therapy with different cell types $[8,103]$. In clinical studies, most of the available data come from bone marrow cell therapies for malignant and nonmalignant diseases [104,105]. A meta-analysis of 50 clinical trials using cell therapies for acute and chronic ischemic heart disease with a total of 2625 patients has found that bone marrow cell treatment improves left ventricle (LV) ejection fraction, infarct size, LV end-diastolic volume, and LV end-systolic volume [106]. A recent trial investigating the 


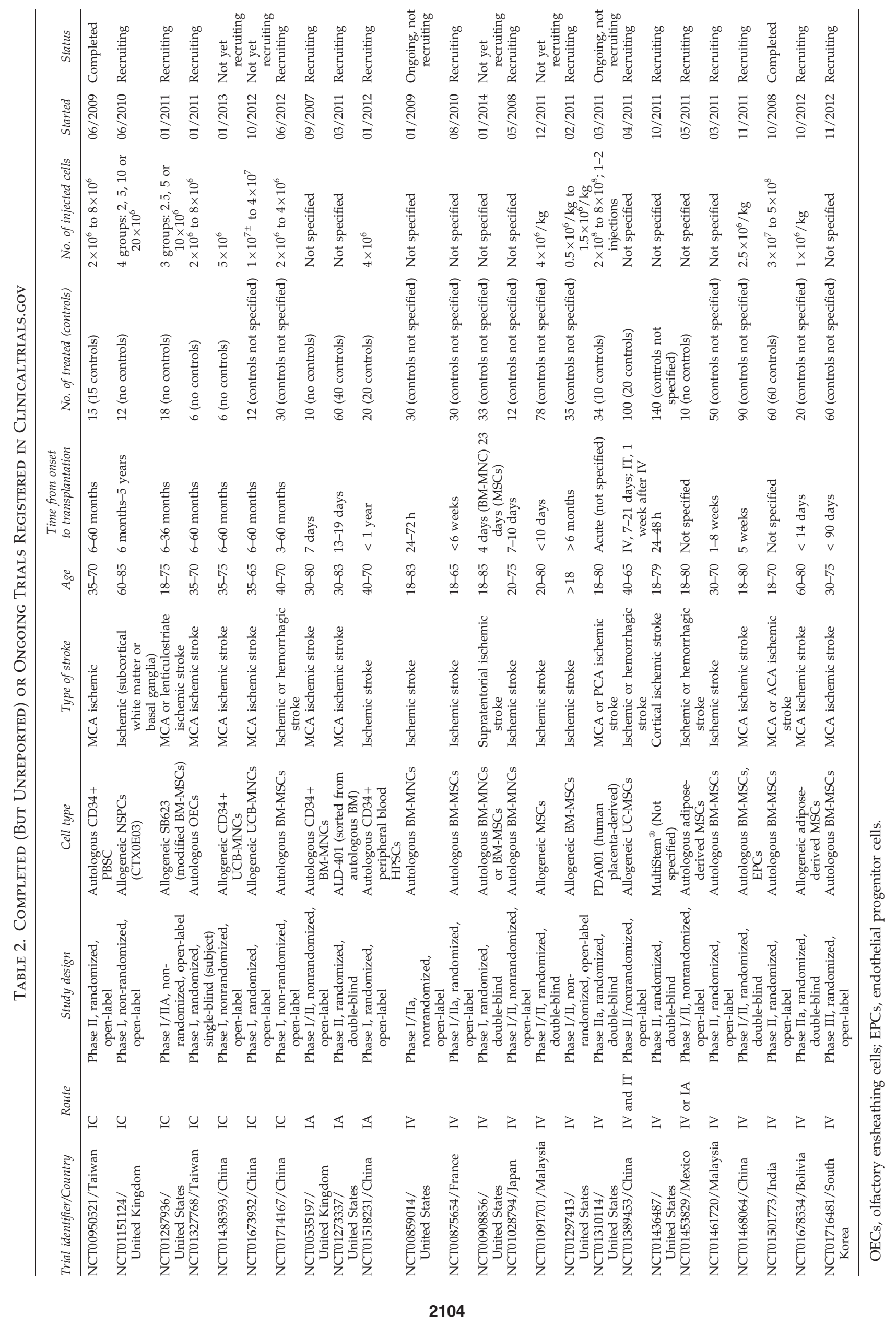




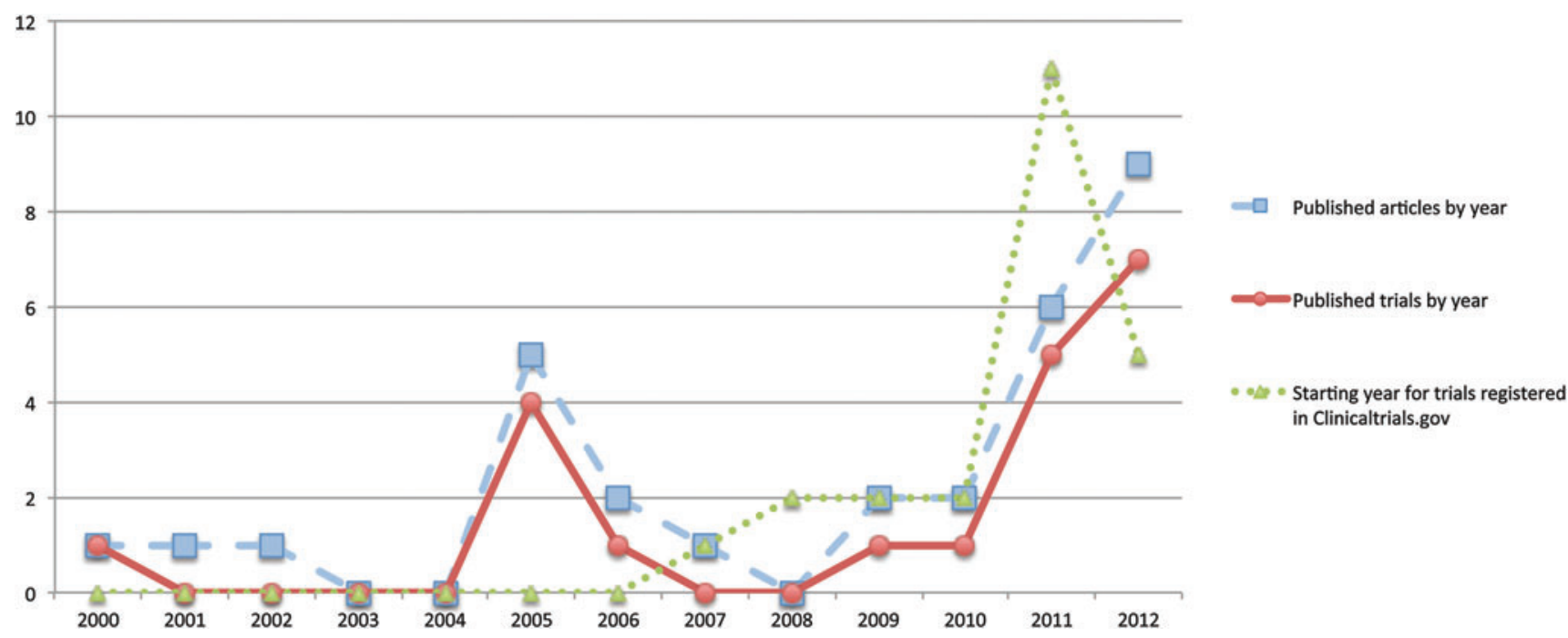

FIG. 2. Graph illustrating the increase in published articles by year, published trials by year, and starting the year for trials registered in www.clinicaltrials.gov from 2000 to 2012. Color images available online at www.liebertpub.com/scd

transendocardial injection of autologous or allogeneic BMMSCs in 30 patients with ischemic cardiomyopathy improved ventricular remodeling, functional capacity, and quality of life, with a 13-month follow-up [107]. For peripheral artery disease, a meta-analysis of 37 trials involving injection of bone marrow cells, peripheral blood cells, or GCSF indicated that cell therapies, but not G-CSF, significantly improved the indices of ischemia such as the ankle-brachial index, transcutaneous oxygen tension, pain-free walking distance, and also hard endpoints such as ulcer healing and amputation [108].

Although clinical results with other ischemic diseases and preclinical studies for stroke are encouraging, there are still many questions regarding the possible mechanisms of action of the cells and the optimal treatment protocol. One of the main questions to be answered is related to the best cell type to be used in these patients. A recent meta-analysis of 117 preclinical stroke studies indicated that for structural effects, autologous stem cells were more effective than allogeneic cells, while for functional effects, allogeneic cells were more effective [109]. Interestingly, the authors found no difference between the embryonic and adult allogeneic cells for either structural or functional outcomes. This would support the use of adult cells rather than embryonic or fetal-derived cells; the former are preferred because of the ethics concerns associated with the latter. Moreover, bone marrow cells can be harvested from the patient for autologous therapy, avoiding the necessity for immunosuppressants $[7,103]$.

To optimize future cell therapies for stroke, it is also necessary to elucidate the molecular mechanisms controlling the interaction of the grafted cells with the ischemic brain. Cerebral ischemia is immediately followed by microvascular dysfunction, oxidative stress, blood-brain barrier disruption, and excitotoxicity. These events are accompanied by the release of endogenous danger signals to the extracellular environment, the activation of the innate immune system, and the infiltration of blood leukocytes into the brain [110]. In this scenario, the interaction of transplanted cells with the ischemic tissue is mediated by a wide range of receptors, such as Toll-like receptors (TLRs), adenosine receptors, and chemokine receptors, which are activated upon the exposure to danger-associated molecular patterns and other inflammatory mediators released during the acute/subacute phases of stroke. It has been demonstrated that several chemokine receptors are involved in the recruitment of BM-MSCs and NSPC to the ischemic brain $[45,111,112]$, and that TLR-2 mediates VEGF production and the recovery of myocardial function by transplanted BM-MSCs [113]. Thus, the postischemic environment can affect the function of transplanted stem/progenitor cells, which in turn can modulate the inflammatory response and the local microenvironment, as discussed above. Although it has been shown that human NSPC and iPS-derived long-term expandable neuroepitheliallike stem cells can give rise to functional neurons, when transplanted $48 \mathrm{~h}$ after stroke in T-cell-deficient rats [114,115], it is still poorly understood how the postischemic environment affects the survival, the proliferation, and the differentiation of transplanted NSPC. In one interesting study, for example, IL-6 preconditioning increased the survival of murine NSPC transplanted in the ischemic penumbra $6 \mathrm{~h}$ after the injury [116], suggesting that pharmacological or genetic manipulations could be used to improve the effectiveness of cell therapies for stroke.

Regarding the timing of transplantation, preclinical studies have shown that cell therapy increases functional recovery after acute, subacute, and chronic stroke [103], but few studies have compared different time windows, with differing results according to the model and cell type studied. In an animal model of focal ischemia, de Vasconcelos dos Santos et al. [59] found significant improvement in the cylinder test after intravenous injection of BM-MNCs at 1 and 7 days or BM-MSCs at 1 day after ischemia, but not in animals treated 30 days after the lesion. In a model of MCA occlusion (MCAO), Yang et al. [117] described improvement in the cylinder and corner tests if BM-MNC injection was performed at 1 or 3 days, but not at 28 days after the lesion. Also in a model of MCAO, Komatsu and colleagues [118] found a reduction of the ischemic lesion volume if BM-MSC therapy 
was performed at 7 days, but not at 14 or 28 days, while improvement in angiogenesis and the treadmill stess test occurred if cell transplantation was carried out up to 28 days after MCAO. In their meta-analysis of different preclinical studies, Lees and collaborators [109] found an absolute reduction in the efficacy of $1.5 \%$ for each day of delay of treatment for structural outcome, while improvement of functional outcome occurred in both early and late time windows [109].

The appropriate dose to use in clinical trials also remains unclear. The Stem Cell Therapies as an Emerging Paradigm in Stroke (STEPS) guidelines recommended a weight-based translation of cell dose from animal studies. In clinical studies of acute myocardial infarction, a metaregression indicated a dose-response correlation between the amount of CD34 + cells injected and the improvement in LVEF. A doseresponse has also been reported by different preclinical studies for stroke $[109,117,119]$, but has not been reported in the small clinical trials.

Cell tracking and imaging is also an important aspect to consider, since these techniques may improve understanding of several components of the therapy such as, cell homing, biodistribution, survival, and cell fate. One of the most often used approaches is labeling with radiopharmaceuticals for PET or SPECT imaging or exogenous contrasts such as iron oxide for MRI.

A small number of preclinical studies have compared different routes of injection, with discordant results depending on the experimental model and the moment of transplantation. Even though intracerebral transplantation may allow greater cell homing than intravascular injection, it is an invasive method and leads to poor cell distribution in the lesion [120,121]. IA administration can lead to a significant decrease in the cerebral blood flow, as assessed by laser Doppler flow, and increase in the mortality rate $[120,121]$. Kamiya and collaborators [122] found that IA injection of $\mathrm{BM}-\mathrm{MNC}$ resulted in greater brain cell retention and better functional outcomes compared to IV injection in a model of transient ischemia. Vasconcelos-dos-Santos et al. [123] reported that IV and IA infusions of these cells led to an equivalent functional recovery with low brain homing, in a model of permanent ischemia. Zhang et al. [124] found that IA, IV, IC, intra-cisterna magna, and lumbar intrathecal injection of human umbilical tissue-derived cells in a model of stroke led to similar structural improvements. The only meta-analysis of preclinical trials for stroke found no important impact of the delivery route on the efficacy of cell therapy [109]. In clinical trials, significant stenosis or occlusion of intracranial circulation is often an exclusion criterion, but it is possible that collateral supply may allow cells to reach the lesioned region [125].

Another aspect that must be clarified is the appropriate injection rate of the cells, and the potential effects of heparin or iodine contrast. A preclinical study by El-Khoury et al. [126] found that the IA flow rates of $5 \mathrm{~mL} / \mathrm{min}$ reduced BMMNC viability by $19 \%$, while the rates of $2 \mathrm{~mL} / \mathrm{min}$ did not affect viability or cytokine production. Although iodine and low-dose heparin exposure did not reduce cell viability, high doses of heparin were cytotoxic. With respect to IC and IV administration, information is lacking on the effects of injection rate from preclinical studies. In clinical trials published to date, the majority of studies did not report either the volume or the duration of injection (Table 1).
In addition to the different aspects previously mentioned, it is extremely important to strictly assess the safety of cell therapies. Although the currently published clinical studies indicate that cell therapies for stroke seem to be safe and feasible, there is a lack of robust scientific data, and many questions remain unanswered. For instance, the risk of teratoma formation with pluripotent stem cells must be addressed. In a recent report, Ben-David and collaborators carried out a high-throughput screen of 52,000 small molecules in cultures of different human ploripotent stem cells and identified 15 pluripotent cell-specific inhibitors, one of which prevented teratoma formation [127]. It is also important to evaluate the influence of clinical variables such as the presence of comorbidities. A preclinical study by Chen et al. indicated that BM-MSC injection $24 \mathrm{~h}$ after MCAO did not improve the functional outcome in Type 1 diabetic rats and increased arteriosclerosis, cerebral artery neointimal formation, and blood-brain barrier leakage [128], but this remains to be evaluated in a clinical study. Another facet that deserves attention is the influence of administering factors such as G-CSF. Clinical studies with the injection of G-CSF in patients with stroke indicate that the procedure seems to be safe [102,129-134], but only the study by England and collaborators [102] evaluated the effects of CD34 ${ }^{+}$cell transplantation after G-CSF injection. Other safety attributes such as the genetic stability and immunogenicity of cells must also be observed and have been thoroughly reviewed in an excellent article by Goldring et al. [135]. Observing such aspects will not mean a delay for the field and at the same time will allow a responsible and adequate development of cell therapies for stroke.

\section{Conclusion}

The results from preclinical studies have indicated that cell therapies can lead to the structural and functional benefits after a stroke. However, there is still a need to examine the ideal subset of stem cells to be used. Further, aspects such as the mechanisms for such improvements and the optimal treament protocol are not yet fully understood and require further evaluation. Nevertheless, different clinical studies, the majority of them small, nonrandomized and uncontrolled, have now been reported and indicate that cell therapy seems safe, feasible, and potentially efficacious. The increasing number of ongoing studies, including large randomized double-blind studies, have the potential to determine the efficacy of cell therapy for stroke and to translate the preclinical findings into clinical practice.

\section{Acknowledgments}

Dr. Rosalia Mendez-Otero was supported by a grant (PP SUS-2009 110.776/2010) from the Ministry of Health and the Fundação Carlos Chagas Filho de Amparo à Pesquisa do Estado do Rio de Janeiro (FAPERJ). Paulo Henrique Rosado-de-Castro received a PhD Scholarship from the Coordenação de Aperfeiçoamento de Pessoal de Nível Superior (CAPES).

The authors wish to thank Janet W. Reid for revising and editing the language in the text and Fernando Brandi for the drawings in Figure 1. 


\section{Author Disclosure Statement}

No competing financial interests exist.

\section{References}

1. Lozano R, M Naghavi, K Foreman, S Lim, K Shibuya, V Aboyans, J Abraham, T Adair, R Aggarwal, et al. (2013). Global and regional mortality from 235 causes of death for 20 age groups in 1990 and 2010: a systematic analysis for the Global Burden of Disease Study 2010. Lancet 380:20952128.

2. Donnan GA, M Fisher, M Macleod and SM Davis. (2008). Stroke. Lancet 371:1612-1623.

3. Strong K, C Mathers and R Bonita. (2007). Preventing stroke: saving lives around the world. Lancet Neurol 6:182-187.

4. Murray CJ, T Vos, R Lozano, M Naghavi, AD Flaxman, C Michaud, M Ezzati, K Shibuya, JA Salomon, et al. (2013). Disability-adjusted life years (DALYs) for 291 diseases and injuries in 21 regions, 1990-2010: a systematic analysis for the Global Burden of Disease Study 2010. Lancet 380:21972223.

5. Molina CA. (2011). Reperfusion therapies for acute ischemic stroke: current pharmacological and mechanical approaches. Stroke 42:S16-S19.

6. Hacke W, G Donnan, C Fieschi, M Kaste, R von Kummer, JP Broderick, T Brott, M Frankel, JC Grotta, et al. (2004). Association of outcome with early stroke treatment: pooled analysis of ATLANTIS, ECASS, and NINDS rt-PA stroke trials. Lancet 363:768-774.

7. Hess DC and WD Hill. (2011). Cell therapy for ischaemic stroke. Cell Prolif 44 Suppl 1:1-8.

8. Mendez-Otero R, GR de Freitas, C Andre, ML de Mendonca, M Friedrich and J Oliveira-Filho. (2007). Potential roles of bone marrow stem cells in stroke therapy. Regen Med 2:417-423.

9. Misra V, A Lal, R El Khoury, PR Chen and SI Savitz. (2012). Intra-arterial delivery of cell therapies for stroke. Stem Cells Dev 21:1007-1015.

10. Vahidy FS, S Alderman and SI Savitz. (2013). Challenges enrolling patients with acute ischemic stroke into cell therapy trials. Stem Cells Dev 22:27-30.

11. Thwaites JW, V Reebye, P Mintz, N Levicar and N Habib. (2012). Cellular replacement and regenerative medicine therapies in ischemic stroke. Regen Med 7:387-395.

12. Glover LE, N Tajiri, NL Weinbren, H Ishikawa, K Shinozuka, Y Kaneko, DM Watterson and CV Borlongan. (2012). A step-up approach for cell therapy in stroke: translational hurdles of bone marrow-derived stem cells. Transl Stroke Res 3:90-98.

13. Lindvall O and Z Kokaia. (2011). Stem cell research in stroke: how far from the clinic? Stroke 42:2369-2375.

14. Kukekov VG, ED Laywell, O Suslov, K Davies, B Scheffler, LB Thomas, TF O'Brien, M Kusakabe and DA Steindler. (1999). Multipotent stem/progenitor cells with similar properties arise from two neurogenic regions of adult human brain. Exp Neurol 156:333-344.

15. Sanai N, AD Tramontin, A Quinones-Hinojosa, NM Barbaro, N Gupta, S Kunwar, MT Lawton, MW McDermott, AT Parsa, et al. (2004). Unique astrocyte ribbon in adult human brain contains neural stem cells but lacks chain migration. Nature 427:740-744.

16. Azevedo-Pereira RL, E Medei, R Mendez-Otero, JP Souza and SV Alves-Leon. (2010). Isolation of neurosphere-like bodies from an adult patient with refractory temporal lobe epilepsy. Arq Neuropsiquiatr 68:956-958.

17. Lindvall $\mathrm{O}$ and Z Kokaia. (2009). Prospects of stem cell therapy for replacing dopamine neurons in Parkinson's disease. Trends Pharmacol Sci 30:260-267.

18. Liu F, Y You, X Li, T Ma, Y Nie, B Wei, T Li, H Lin and Z Yang. (2009). Brain injury does not alter the intrinsic differentiation potential of adult neuroblasts. J Neurosci 29:5075-5087.

19. Seminatore C, J Polentes, D Ellman, N Kozubenko, V Itier, S Tine, L Tritschler, M Brenot, E Guidou, et al. (2010). The postischemic environment differentially impacts teratoma or tumor formation after transplantation of human embryonic stem cell-derived neural progenitors. Stroke 41:153-159.

20. Zhao T, ZN Zhang, Z Rong and Y Xu. (2011). Immunogenicity of induced pluripotent stem cells. Nature 474:212-215.

21. Araki R, M Uda, Y Hoki, M Sunayama, M Nakamura, $S$ Ando, M Sugiura, H Ideno, A Shimada, A Nifuji and M Abe. (2013). Negligible immunogenicity of terminally differentiated cells derived from induced pluripotent or embryonic stem cells. Nature 494:100-104.

22. Fairchild PJ. (2010). The challenge of immunogenicity in the quest for induced pluripotency. Nat Rev Immunol 10:868-875.

23. Vierbuchen T, A Ostermeier, ZP Pang, Y Kokubu, TC Sudhof and M Wernig. (2010). Direct conversion of fibroblasts to functional neurons by defined factors. Nature 463:1035-1041.

24. Han DW, N Tapia, A Hermann, K Hemmer, S Hoing, MJ Arauzo-Bravo, H Zaehres, G Wu, S Frank, et al. (2012). Direct reprogramming of fibroblasts into neural stem cells by defined factors. Cell Stem Cell 10:465-472.

25. Lujan E, S Chanda, H Ahlenius, TC Sudhof and M Wernig. (2012). Direct conversion of mouse fibroblasts to selfrenewing, tripotent neural precursor cells. Proc Natl Acad Sci (USA) 109:2527-2532.

26. Kondziolka D, L Wechsler, S Goldstein, C Meltzer, KR Thulborn, J Gebel, P Jannetta, S DeCesare, EM Elder, et al. (2000). Transplantation of cultured human neuronal cells for patients with stroke. Neurology 55:565-569.

27. Newman MB, I Misiuta, AE Willing, T Zigova, RC Karl, CV Borlongan and PR Sanberg. (2005). Tumorigenicity issues of embryonic carcinoma-derived stem cells: relevance to surgical trials using NT2 and hNT neural cells. Stem Cells Dev 14:29-43.

28. Nelson PT, D Kondziolka, L Wechsler, S Goldstein, J Gebel, S DeCesare, EM Elder, PJ Zhang, A Jacobs, et al. (2002). Clonal human (hNT) neuron grafts for stroke therapy: neuropathology in a patient 27 months after implantation. Am J Pathol 160:1201-1206.

29. Kondziolka D, GK Steinberg, L Wechsler, CC Meltzer, E Elder, J Gebel, S Decesare, T Jovin, R Zafonte, et al. (2005). Neurotransplantation for patients with subcortical motor stroke: a phase 2 randomized trial. J Neurosurg 103:38-45.

30. Meltzer CC, D Kondziolka, VL Villemagne, L Wechsler, S Goldstein, KR Thulborn, J Gebel, EM Elder, S DeCesare and A Jacobs. (2001). Serial [18F] fluorodeoxyglucose positron emission tomography after human neuronal implantation for stroke. Neurosurgery 49:586-591; discussion 591-582.

31. Pimentel-Coelho PM, PH Rosado-de-Castro, LM da Fonseca and R Mendez-Otero. (2012). Umbilical cord blood mononuclear cell transplantation for neonatal hypoxicischemic encephalopathy. Pediatr Res 71:464-473. 
32. Dominici M, K Le Blanc, I Mueller, I Slaper-Cortenbach, F Marini, D Krause, R Deans, A Keating, D Prockop and E Horwitz. (2006). Minimal criteria for defining multipotent mesenchymal stromal cells. The International Society for Cellular Therapy position statement. Cytotherapy 8:315-317.

33. Zhang X, M Hirai, S Cantero, R Ciubotariu, L Dobrila, A Hirsh, K Igura, H Satoh, I Yokomi, et al. (2011). Isolation and characterization of mesenchymal stem cells from human umbilical cord blood: reevaluation of critical factors for successful isolation and high ability to proliferate and differentiate to chondrocytes as compared to mesenchymal stem cells from bone marrow and adipose tissue. J Cell Biochem 112:1206-1218.

34. Guzman R, N Uchida, TM Bliss, D He, KK Christopherson, D Stellwagen, A Capela, J Greve, RC Malenka, et al. (2007). Long-term monitoring of transplanted human neural stem cells in developmental and pathological contexts with MRI. Proc Natl Acad Sci (USA) 104:10211-10216.

35. Daadi MM, Z Li, A Arac, BA Grueter, M Sofilos, RC Malenka, JC Wu and GK Steinberg. (2009). Molecular and magnetic resonance imaging of human embryonic stem cell-derived neural stem cell grafts in ischemic rat brain Mol Ther 17:1282-1291.

36. Lopez-Bendito G and P Arlotta. (2012). Cell replacement therapies for nervous system regeneration. Dev Neurobiol 72:145-152.

37. Lu P, LL Jones, EY Snyder and MH Tuszynski. (2003). Neural stem cells constitutively secrete neurotrophic factors and promote extensive host axonal growth after spinal cord injury. Exp Neurol 181:115-129.

38. Andres RH, N Horie, W Slikker, H Keren-Gill, K Zhan, G Sun, NC Manley, MP Pereira, LA Sheikh, et al. (2011). Human neural stem cells enhance structural plasticity and axonal transport in the ischaemic brain. Brain 134:17771789.

39. Hawryluk GW, AJ Mothe, M Chamankhah, J Wang, C Tator and MG Fehlings. (2012). In vitro characterization of trophic factor expression in neural precursor cells. Stem Cells Dev 21:432-447.

40. Horie N, MP Pereira, K Niizuma, G Sun, H Keren-Gill, A Encarnacion, M Shamloo, SA Hamilton, K Jiang, et al. (2011). Transplanted stem cell-secreted VEGF effects poststroke recovery, inflammation, and vascular repair. Stem Cells 29:274-285.

41. Mosher KI, RH Andres, T Fukuhara, G Bieri, M HasegawaMoriyama, Y He, R Guzman and T Wyss-Coray. (2012). Neural progenitor cells regulate microglia functions and activity. Nat Neurosci 15:1485-1487.

42. Bacigaluppi M, S Pluchino, L Peruzzotti-Jametti, E Kilic, U Kilic, G Salani, E Brambilla, MJ West, G Comi, G Martino and DM Hermann. (2009). Delayed post-ischaemic neuroprotection following systemic neural stem cell transplantation involves multiple mechanisms. Brain 132:2239-2251.

43. Guzman R, A De Los Angeles, S Cheshier, R Choi, S Hoang, J Liauw, B Schaar and G Steinberg. (2008). Intracarotid injection of fluorescence activated cell-sorted CD49d-positive neural stem cells improves targeted cell delivery and behavior after stroke in a mouse stroke model. Stroke 39:1300-1306.

44. Smith EJ, RP Stroemer, N Gorenkova, M Nakajima, WR Crum, E Tang, L Stevanato, JD Sinden and M Modo. (2012). Implantation site and lesion topology determine efficacy of a human neural stem cell line in a rat model of chronic stroke. Stem Cells 30:785-796.
45. Andres RH, R Choi, AV Pendharkar, X Gaeta, N Wang, JK Nathan, JY Chua, SW Lee, TD Palmer, GK Steinberg and R Guzman. (2011). The CCR2/CCL2 interaction mediates the transendothelial recruitment of intravascularly delivered neural stem cells to the ischemic brain. Stroke 42:29232931.

46. Lee ST, K Chu, KH Jung, SJ Kim, DH Kim, KM Kang, NH Hong, JH Kim, JJ Ban, et al. (2008). Anti-inflammatory mechanism of intravascular neural stem cell transplantation in haemorrhagic stroke. Brain 131:616-629.

47. Park DH, DJ Eve, PR Sanberg, J Musso, 3rd, AD Bachstetter, A Wolfson, A Schlunk, MO Baradez, JD Sinden and C Gemma. (2010). Increased neuronal proliferation in the dentate gyrus of aged rats following neural stem cell implantation. Stem Cells Dev 19:175-180.

48. Roybon L, Z Ma, F Asztely, A Fosum, SE Jacobsen, P Brundin and JY Li. (2006). Failure of transdifferentiation of adult hematopoietic stem cells into neurons. Stem Cells 24:1594-1604.

49. Barnabe GF, TT Schwindt, ME Calcagnotto, FL Motta, G Martinez, Jr., AC de Oliveira, LM Keim, V D'Almeida, R Mendez-Otero and LE Mello. (2009). Chemically-induced RAT mesenchymal stem cells adopt molecular properties of neuronal-like cells but do not have basic neuronal functional properties. PLoS One 4:e5222.

50. Vallieres L and PE Sawchenko. (2003). Bone marrowderived cells that populate the adult mouse brain preserve their hematopoietic identity. J Neurosci 23:5197-5207.

51. Schwarting S, S Litwak, W Hao, M Bahr, J Weise and H Neumann. (2008). Hematopoietic stem cells reduce postischemic inflammation and ameliorate ischemic brain injury. Stroke 39:2867-2875.

52. Mitkari B, E Kerkela, J Nystedt, M Korhonen, V Mikkonen, T Huhtala and J Jolkkonen. (2012). Intra-arterial infusion of human bone marrow-derived mesenchymal stem cells results in transient localization in the brain after cerebral ischemia in rats. Exp Neurol 239C:158-162.

53. Borlongan CV, M Hadman, CD Sanberg and PR Sanberg. (2004). Central nervous system entry of peripherally injected umbilical cord blood cells is not required for neuroprotection in stroke. Stroke 35:2385-2389.

54. Vendrame M, C Gemma, D de Mesquita, L Collier, PC Bickford, CD Sanberg, PR Sanberg, KR Pennypacker and AE Willing. (2005). Anti-inflammatory effects of human cord blood cells in a rat model of stroke. Stem Cells Dev 14:595-604.

55. Vendrame M, C Gemma, KR Pennypacker, PC Bickford, C Davis Sanberg, PR Sanberg and AE Willing. (2006). Cord blood rescues stroke-induced changes in splenocyte phenotype and function. Exp Neurol 199:191-200.

56. Ohtaki H, JH Ylostalo, JE Foraker, AP Robinson, RL Reger, S Shioda and DJ Prockop. (2008). Stem/progenitor cells from bone marrow decrease neuronal death in global ischemia by modulation of inflammatory/immune responses. Proc Natl Acad Sci (USA) 105:14638-14643.

57. Giraldi-Guimaraes A, M Rezende-Lima, FP Bruno and R Mendez-Otero. (2009). Treatment with bone marrow mononuclear cells induces functional recovery and decreases neurodegeneration after sensorimotor cortical ischemia in rats. Brain Res 1266:108-120.

58. Chopp M, Y Li and ZG Zhang. (2009). Mechanisms underlying improved recovery of neurological function after stroke in the rodent after treatment with neurorestorative cell-based therapies. Stroke 40:S143-S145. 
59. de Vasconcelos Dos Santos A, J da Costa Reis, B Diaz Paredes, L Moraes, Jasmin, A Giraldi-Guimaraes and R Mendez-Otero. (2010). Therapeutic window for treatment of cortical ischemia with bone marrow-derived cells in rats. Brain Res 1306:149-158.

60. Brenneman M, S Sharma, M Harting, R Strong, CS Cox, Jr., J Aronowski, JC Grotta and SI Savitz. (2010). Autologous bone marrow mononuclear cells enhance recovery after acute ischemic stroke in young and middle-aged rats. J Cereb Blood Flow Metab 30:140-149.

61. Yasuhara T, N Matsukawa, K Hara, M Maki, MM Ali, SJ Yu, E Bae, G Yu, L Xu, et al. (2009). Notch-induced rat and human bone marrow stromal cell grafts reduce ischemic cell loss and ameliorate behavioral deficits in chronic stroke animals. Stem Cells Dev 18:1501-1514.

62. Xiao J, Z Nan, Y Motooka and WC Low. (2005). Transplantation of a novel cell line population of umbilical cord blood stem cells ameliorates neurological deficits associated with ischemic brain injury. Stem Cells Dev 14:722-733.

63. Newman MB, AE Willing, JJ Manresa, C Davis-Sanberg and PR Sanberg. (2005). Stroke-induced migration of human umbilical cord blood cells: time course and cytokines. Stem Cells Dev 14:576-586.

64. Bakondi B, IS Shimada, BM Peterson and JL Spees. (2011). SDF-1alpha secreted by human CD133-derived multipotent stromal cells promotes neural progenitor cell survival through CXCR7. Stem Cells Dev 20:1021-1029.

65. Taguchi A, T Soma, H Tanaka, T Kanda, H Nishimura, H Yoshikawa, Y Tsukamoto, H Iso, Y Fujimori, et al. (2004). Administration of CD34 + cells after stroke enhances neurogenesis via angiogenesis in a mouse model. J Clin Invest 114:330-338.

66. Bao X, M Feng, J Wei, Q Han, H Zhao, G Li, Z Zhu, H Xing, Y An, et al. (2011). Transplantation of Flk-1 + human bone marrow-derived mesenchymal stem cells promotes angiogenesis and neurogenesis after cerebral ischemia in rats. Eur J Neurosci 34:87-98.

67. Goldman SA and Z Chen. (2011). Perivascular instruction of cell genesis and fate in the adult brain. Nat Neurosci 14:1382-1389.

68. Lin YC, TL Ko, YH Shih, MY Lin, TW Fu, HS Hsiao, JY Hsu and YS Fu. (2011). Human umbilical mesenchymal stem cells promote recovery after ischemic stroke. Stroke 42:2045-2053.

69. Ranganath SH, O Levy, MS Inamdar and JM Karp. (2012). Harnessing the mesenchymal stem cell secretome for the treatment of cardiovascular disease. Cell Stem Cell 10: 244-258.

70. Xin H, Y Li, B Buller, M Katakowski, Y Zhang, X Wang, X Shang, ZG Zhang and M Chopp. (2012). Exosomemediated transfer of miR-133b from multipotent mesenchymal stromal cells to neural cells contributes to neurite outgrowth. Stem Cells 30:1556-1564.

71. van Velthoven CT, A Kavelaars, F van Bel and CJ Heijnen. (2010). Repeated mesenchymal stem cell treatment after neonatal hypoxia-ischemia has distinct effects on formation and maturation of new neurons and oligodendrocytes leading to restoration of damage, corticospinal motor tract activity, and sensorimotor function. J Neurosci 30:96039611.

72. Yang B, X Xi, J Aronowski and SI Savitz. (2012). Ischemic stroke may activate bone marrow mononuclear cells to enhance recovery after stroke. Stem Cells Dev. 21:33323340.
73. Fan Y, F Shen, T Frenzel, W Zhu, J Ye, J Liu, Y Chen, H Su, WL Young and GY Yang. (2010). Endothelial progenitor cell transplantation improves long-term stroke outcome in mice. Ann Neurol 67:488-497.

74. Nih LR, N Deroide, C Lere-Dean, D Lerouet, M Soustrat, BI Levy, JS Silvestre, T Merkulova-Rainon, M Pocard, I Margaill and N Kubis. (2012). Neuroblast survival depends on mature vascular network formation after mouse stroke: role of endothelial and smooth muscle progenitor cell $\mathrm{Co}^{-}$ administration. Eur J Neurosci 35:1208-1217.

75. Zhang L, Y Li, C Zhang, M Chopp, A Gosiewska and K Hong. (2011). Delayed administration of human umbilical tissue-derived cells improved neurological functional recovery in a rodent model of focal ischemia. Stroke 42:14371444.

76. Savitz SI, J Dinsmore, J Wu, GV Henderson, P Stieg and LR Caplan. (2005). Neurotransplantation of fetal porcine cells in patients with basal ganglia infarcts: a preliminary safety and feasibility study. Cerebrovasc Dis 20:101-107.

77. Suarez-Monteagudo C, P Hernandez-Ramirez, L AlvarezGonzalez, I Garcia-Maeso, K de la Cuetara-Bernal, L Castillo-Diaz, ML Bringas-Vega, G Martinez-Aching, LM Morales-Chacon, et al. (2009). Autologous bone marrow stem cell neurotransplantation in stroke patients. An open study. Restor Neurol Neurosci 27:151-161.

78. Bringas ML, C Suarez, C Sanchez, LM Alvarez, P Valdes, S Salazar, D Chongo and M Jahanshahi. (2011). Cognitive changes after stem cell transplantation in a patient with subcortical stroke. BMJ Case Rep. DOI: http://dx.doi.org/ 10.1136/bcr.03.2011.3944.

79. Li ZM, ZT Zhang, CJ Guo, FY Geng, F Qiang and LX Wang. (2013). Autologous bone marrow mononuclear cell implantation for intracerebral hemorrhage-A prospective clinical observation. Clin Neurol Neurosurg 115:72-76.

80. Rabinovich SS, VI Seledtsov, NV Banul, OV Poveshchenko, VV Senyukov, SV Astrakov, DM Samarin and VY Taraban. (2005). Cell therapy of brain stroke. Bull Exp Biol Med 139:126-128.

81. Sharma A, H Sane, P Badhe, P Kulkarni, G Chopra, M Lohia and N Gokulchandran. (2012). Autologous bone marrow stem cell therapy shows functional improvement in hemorrhagic stroke. Indian J Clin Pract 23:100-105.

82. Han H, SK Chang, JJ Chang, SH Hwang, SH Han and BH Chun. (2011). Intrathecal injection of human umbilical cord blood-derived mesenchymal stem cells for the treatment of basilar artery dissection: a case report. J Med Case Rep 5:562.

83. Correa P, R Felix, ML Mendonca, G Freitas, J Azevedo, H Dohmann, S Alves and C Mesquita. (2005). Dual-head coincidence gamma camera FDG-PET before and after autologous bone marrow mononuclear cell implantation in ischaemic stroke. Eur J Nucl Med Mol Imaging 32: 999.

84. Mendonca ML, GR Freitas, SA Silva, A Manfrim, CH Falcao, C Gonzales, C Andre, HF Dohmann, R Borojevic and RM Otero. (2006). [Safety of intra-arterial autologous bone marrow mononuclear cell transplantation for acute ischemic stroke]. Arq Bras Cardiol 86:52-55.

85. Correa PL, CT Mesquita, RM Felix, JC Azevedo, GB Barbirato, CH Falcao, C Gonzalez, ML Mendonca, A Manfrim, et al. (2007). Assessment of intra-arterial injected autologous bone marrow mononuclear cell distribution by radioactive labeling in acute ischemic stroke. Clin Nucl Med 32:839-841. 
86. Barbosa da Fonseca LM, V Battistella, GR de Freitas, B Gutfilen, RC Dos Santos Goldenberg, A Maiolino, E Wajnberg, PH Rosado de Castro, R Mendez-Otero and C Andre. (2009). Early tissue distribution of bone marrow mononuclear cells after intra-arterial delivery in a patient with chronic stroke. Circulation 120:539-541.

87. Barbosa da Fonseca LM, B Gutfilen, PH Rosado de Castro, V Battistella, RC Goldenberg, T Kasai-Brunswick, CL Chagas, E Wajnberg, A Maiolino, et al. (2010). Migration and homing of bone-marrow mononuclear cells in chronic ischemic stroke after intra-arterial injection. Exp Neurol 221:122-128.

88. Battistella V, GR de Freitas, LM da Fonseca, D Mercante, B Gutfilen, RC Goldenberg, JV Dias, TH Kasai-Brunswick, E Wajnberg, et al. (2011). Safety of autologous bone marrow mononuclear cell transplantation in patients with nonacute ischemic stroke. Regen Med 6:45-52.

89. Rosado de Castro PH, FR Schmidt, V Battistella, SA Lopes de Souza, B Gutfilen, RC Goldenberg, TH Kasai-Brunswick, L Vairo, RM Silva, et al. (2013). Biodistribution of bone marrow mononuclear cells after intra-arterial or intravenous transplantation in subacute stroke patients. Regen Med 8:145-155.

90. Friedrich MA, MP Martins, MD Araujo, C Klamt, L Vedolin, B Garicochea, EF Raupp, JS Ammar, DC Machado, et al. (2012). Intra-arterial infusion of autologous bonemarrow mononuclear cells in patients with moderate to severe middle-cerebral-artery acute ischemic stroke. Cell Transplant 21:S13-S21.

91. Moniche F, A Gonzalez, JR Gonzalez-Marcos, M Carmona, P Pinero, I Espigado, D Garcia-Solis, A Cayuela, J Montaner, et al. (2012). Intra-arterial bone marrow mononuclear cells in ischemic stroke: a pilot clinical trial. Stroke 43:22422244.

92. Jiang Y, W Zhu, J Zhu, L Wu, G Xu and X Liu. (2012). Feasibility of delivering mesenchymal stem cells via catheter to the proximal end of lesion artery in patients with stroke in the territory of middle cerebral artery. Cell Transplant. [Epub ahead of print]; DOI: 10.3727/096368912X658818.

93. Man Y, J Li, B Yang and J Ma. (2006). Vein transplantation using human umbilical cord blood stem cells in the treatment of stroke sequela. Neural Regen Res 1:618-621.

94. Bang OY, JS Lee, PH Lee and G Lee. (2005). Autologous mesenchymal stem cell transplantation in stroke patients. Ann Neurol 57:874-882.

95. Lee JS, JM Hong, GJ Moon, PH Lee, YH Ahn, OY Bang and S collaborators. (2010). A long-term follow-up study of intravenous autologous mesenchymal stem cell transplantation in patients with ischemic stroke. Stem Cells 28:1099_ 1106.

96. Honmou O, K Houkin, T Matsunaga, Y Niitsu, S Ishiai, R Onodera, SG Waxman and JD Kocsis. (2011). Intravenous administration of auto serum-expanded autologous mesenchymal stem cells in stroke. Brain 134:1790-1807.

97. Bhasin A, MV Srivastava, SS Kumaran, S Mohanty, R Bhatia, S Bose, S Gaikwad, A Garg and B Airan. (2011). Autologous mesenchymal stem cells in chronic stroke. Cerebrovasc Dis Extra 1:93-104.

98. Savitz SI, V Misra, M Kasam, H Juneja, CS Cox, Jr., S Alderman, I Aisiku, S Kar, A Gee and JC Grotta. (2011). Intravenous autologous bone marrow mononuclear cells for ischemic stroke. Ann Neurol 70:59-69.

99. Prasad K, S Mohanty, R Bhatia, MV Srivastava, A Garg, A Srivastava, V Goyal, M Tripathi, A Kumar, et al. (2012).
Autologous intravenous bone marrow mononuclear cell therapy for patients with subacute ischaemic stroke: A pilot study. Indian J Med Res 136:221-228.

100. Bhasin A, MV Srivastava, R Bhatia, S Mohanty, SS Kumaran and S Bose. (2012a). Autologous intravenous mononuclear stem cell therapy in chronic ischemic stroke. J Stem Cells Regen Med 8:181-189.

101. Bhasin A, MV Padma Srivastava, S Mohanty, R Bhatia, SS Kumaran and S Bose. (2012b). Stem cell therapy: A clinical trial of stroke. Clin Neurol Neurosurg. In Press.

102. England TJ, M Abaei, DP Auer, J Lowe, DR Jones, G Sare, M Walker and PM Bath. (2012). Granulocyte-colony stimulating factor for mobilizing bone marrow stem cells in subacute stroke: the stem cell trial of recovery enhancement after stroke 2 randomized controlled trial. Stroke 43:405411.

103. Bliss TM, RH Andres and GK Steinberg. (2010). Optimizing the success of cell transplantation therapy for stroke. Neurobiol Dis 37:275-283.

104. Burt RK, Y Loh, W Pearce, N Beohar, WG Barr, R Craig, Y Wen, JA Rapp and J Kessler. (2008). Clinical applications of blood-derived and marrow-derived stem cells for nonmalignant diseases. JAMA 299:925-936.

105. Resnick IB, MY Shapira and S Slavin. (2005). Nonmyeloablative stem cell transplantation and cell therapy for malignant and non-malignant diseases. Transpl Immunol 14:207-219.

106. Jeevanantham V, M Butler, A Saad, A Abdel-Latif, EK Zuba-Surma and B Dawn. (2012). Adult bone marrow cell therapy improves survival and induces long-term improvement in cardiac parameters: a systematic review and meta-analysis. Circulation 126:551-568.

107. Hare JM, JE Fishman, G Gerstenblith, DL Difede Velazquez, JP Zambrano, VY Suncion, M Tracy, E Ghersin, PV Johnston, et al. (2012). Comparison of Allogeneic vs Autologous Bone Marrow-Derived Mesenchymal Stem Cells Delivered by Transendocardial Injection in Patients With Ischemic Cardiomyopathy: The POSEIDON Randomized Trial. JAMA:1-11.

108. Fadini GP, C Agostini and A Avogaro. (2010). Autologous stem cell therapy for peripheral arterial disease metaanalysis and systematic review of the literature. Atherosclerosis 209:10-17.

109. Lees JS, ES Sena, KJ Egan, A Antonic, SA Koblar, DW Howells and MR Macleod. (2012). Stem cell-based therapy for experimental stroke: a systematic review and metaanalysis. Int J Stroke 7:582-588.

110. Iadecola $C$ and J Anrather. (2011). The immunology of stroke: from mechanisms to translation. Nat Med 17:796-808.

111. Imitola J, K Raddassi, KI Park, FJ Mueller, M Nieto, YD Teng, D Frenkel, J Li, RL Sidman, et al. (2004). Directed migration of neural stem cells to sites of CNS injury by the stromal cell-derived factor 1alpha/CXC chemokine receptor 4 pathway. Proc Natl Acad Sci (USA) 101:18117-18122.

112. Wang Y, Y Deng and GQ Zhou. (2008). SDF-1alpha/ CXCR4-mediated migration of systemically transplanted bone marrow stromal cells towards ischemic brain lesion in a rat model. Brain Res 1195:104-112.

113. Abarbanell AM, Y Wang, JL Herrmann, BR Weil, JA Poynter, MC Manukyan and DR Meldrum. (2010). Toll-like receptor 2 mediates mesenchymal stem cell-associated myocardial recovery and VEGF production following acute ischemia-reperfusion injury. Am J Physiol Heart Circ Physiol 298:H1529-1536. 
114. Mine Y, J Tatarishvili, K Oki, E Monni, Z Kokaia and O Lindvall. (2013). Grafted human neural stem cells enhance several steps of endogenous neurogenesis and improve behavioral recovery after middle cerebral artery occlusion in rats. Neurobiol Dis 52:191-203.

115. Oki K, J Tatarishvili, J Wood, P Koch, S Wattananit, Y Mine, E Monni, D Tornero, H Ahlenius, et al. (2012). Humaninduced pluripotent stem cells form functional neurons and improve recovery after grafting in stroke-damaged brain. Stem Cells 30:1120-1133.

116. Sakata H, P Narasimhan, K Niizuma, CM Maier, T Wakai and PH Chan. (2012). Interleukin 6-preconditioned neural stem cells reduce ischaemic injury in stroke mice. Brain 135:3298-3310.

117. Yang B, R Strong, S Sharma, M Brenneman, K Mallikarjunarao, X Xi, JC Grotta, J Aronowski and SI Savitz. (2011). Therapeutic time window and dose response of autologous bone marrow mononuclear cells for ischemic stroke. J Neurosci Res 89:833-839.

118. Komatsu K, O Honmou, J Suzuki, K Houkin, H Hamada and JD Kocsis. (2010). Therapeutic time window of mesenchymal stem cells derived from bone marrow after cerebral ischemia. Brain Res 1334:84-92.

119. Saporta S, CV Borlongan and PR Sanberg. (1999). Neural transplantation of human neuroteratocarcinoma (hNT) neurons into ischemic rats. A quantitative dose-response analysis of cell survival and behavioral recovery. Neuroscience 91:519-525.

120. Li L, Q Jiang, G Ding, L Zhang, ZG Zhang, Q Li, S Panda, M Lu, JR Ewing and M Chopp. (2010). Effects of administration route on migration and distribution of neural progenitor cells transplanted into rats with focal cerebral ischemia, an MRI study. J Cereb Blood Flow Metab 30:653662.

121. Walczak P, J Zhang, AA Gilad, DA Kedziorek, J RuizCabello, RG Young, MF Pittenger, PC van Zijl, J Huang and JW Bulte. (2008). Dual-modality monitoring of targeted intraarterial delivery of mesenchymal stem cells after transient ischemia. Stroke 39:1569-1574.

122. Kamiya N, M Ueda, H Igarashi, Y Nishiyama, S Suda, T Inaba and Y Katayama. (2008). Intra-arterial transplantation of bone marrow mononuclear cells immediately after reperfusion decreases brain injury after focal ischemia in rats. Life Sci 83:433-437.

123. Vasconcelos-dos-Santos A, PH Rosado-de-Castro, SA Lopes de Souza, J da Costa Silva, AB Ramos, G Rodriguez de Freitas, LM Barbosa da Fonseca, B Gutfilen and R Mendez-Otero. (2012). Intravenous and intra-arterial administration of bone marrow mononuclear cells after focal cerebral ischemia: is there a difference in biodistribution and efficacy? Stem Cell Res 9:1-8.

124. Zhang L, Y Li, M Romanko, BC Kramer, A Gosiewska, M Chopp and K Hong. (2012). Different routes of administration of human umbilical tissue-derived cells improve functional recovery in the rat after focal cerebral ischemia. Brain Res 1489:104-112.

125. de Freitas GR and R Mendez-Otero. (2013). Intra-arterial Cell Therapy in Stroke Patients. In: Cell-Based Therapies in Stroke. Jolkkonen J, P Walczak, eds. Springer, New York, pp 181-190.

126. El Khoury R, V Misra, S Sharma, CS Cox, P Walker, JC Grotta, A Gee, S Suzuki and SI Savitz. (2010). The effect of transcatheter injections on cell viability and cytokine re- lease of mononuclear cells. AJNR Am J Neuroradiol 31: 1488-1492.

127. Ben-David U, QF Gan, T Golan-Lev, P Arora, O Yanuka, YS Oren, A Leikin-Frenkel, M Graf, R Garippa, et al. (2013). Selective elimination of human pluripotent stem cells by an oleate synthesis inhibitor discovered in a high-throughput screen. Cell Stem Cell 12:167-179.

128. Chen J, X Ye, T Yan, C Zhang, XP Yang, X Cui, Y Cui, A Zacharek, C Roberts, et al. (2011). Adverse effects of bone marrow stromal cell treatment of stroke in diabetic rats. Stroke 42:3551-3558.

129. Sprigg N, PM Bath, L Zhao, MR Willmot, LJ Gray, MF Walker, MS Dennis and N Russell. (2006). Granulocytecolony-stimulating factor mobilizes bone marrow stem cells in patients with subacute ischemic stroke: the Stem cell Trial of recovery EnhanceMent after Stroke (STEMS) pilot randomized, controlled trial (ISRCTN 16784092). Stroke 37:2979-2983.

130. Shyu WC, SZ Lin, CC Lee, DD Liu and H Li. (2006). Granulocyte colony-stimulating factor for acute ischemic stroke: a randomized controlled trial. CMAJ 174:927-933.

131. Schabitz WR, R Laage, G Vogt, W Koch, R Kollmar, S Schwab, D Schneider, GF Hamann, M Rosenkranz, et al. (2010). AXIS: a trial of intravenous granulocyte colony-stimulating factor in acute ischemic stroke. Stroke 41:2545-2551.

132. Boy S, S Sauerbruch, M Kraemer, T Schormann, F Schlachetzki, G Schuierer, R Luerding, B Hennemann, E Orso, et al. (2011). Mobilisation of hematopoietic CD34+ precursor cells in patients with acute stroke is safe-results of an open-labeled non randomized phase I/II trial. PLoS One 6:e23099.

133. Floel A, T Warnecke, T Duning, Y Lating, J Uhlenbrock, A Schneider, G Vogt, R Laage, W Koch, S Knecht and WR Schabitz. (2011). Granulocyte-colony stimulating factor (G-CSF) in stroke patients with concomitant vascular disease —a randomized controlled trial. PLoS One 6:e19767.

134. Moriya Y, A Mizuma, T Uesugi, Y Ohnuki, E Nagata, W Takahashi, H Kobayashi, H Kawada, K Ando, S Takagi and S Takizawa. (2012). Phase I Study of intravenous low-dose granulocyte colony-stimulating factor in acute and subacute ischemic stroke. J Stroke Cerebrovasc Dis. [Epub ahead of print]; DOI: 10.1016/j.jstrokecerebrovasdis.2012.08.002.

135. Goldring CE, PA Duffy, N Benvenisty, PW Andrews, U Ben-David, R Eakins, N French, NA Hanley, L Kelly, et al. (2011). Assessing the safety of stem cell therapeutics. Cell Stem Cell 8:618-628.

Address correspondence to: Dr. Paulo Henrique Rosado-de-Castro Hospital Universitário Clementino Fraga Filho Universidade Federal do Rio de Janeiro Rua Professor Rodolpho Paulo Rocco 255 Cidade Universitária Ilha do Fundão

Rio de Janeiro 21941-913 Brazil

E-mail: phrosadodecastro@ufrj.br

Received for publication February 10, 2013

Accepted after revision March 18, 2013

Prepublished on Liebert Instant Online March 19, 2013 